\title{
LA FI DEL DOMINI DE L'ORDE DEL TEMPLE A TORTOSA. LA PERMUTA DE 1294
}

\author{
LAUReÀ Pagarolas I SABATÉ \\ Arxiu Històric de Protocols de Barcelona
}

SUMARI

1. El context: la recuperació del patrimoni reial a la regió de l'Ebre.2. Les causes directes de la permuta.- 3. El contingut i l'abast del canvi.- 4. Les retencions posteriors. Apèndix documental.

\section{EL CONTEXT: \\ LA RECUPERACIÓ DEL PATRIMONI REIAL}

A LA REGIÓ DE L'EBRE

Tot just en el tombant de la tretzena centúria, el segle que precisament havia suposat el punt més àlgid d'expansió en la curta trajectòria històrica de l'Orde del Temple a Catalunya, tenim documentat un fenomen avui per avui no prou estudiat de recuperació de rendes senyorials per part de la Corona. I això potser de manera similar al procés que tindrà lloc un segle després en temps de Martí l'Humà, el qual, en canvi, sí que ha merescut una atenció major per part dels historiadors' ${ }^{\prime}$ o també al que es produí a mitjan segle $\mathrm{XV}$, després de les

\footnotetext{
'Vegeu, principalment, l'excel-lent treball de Maria Teresa Ferrer I Mallol, El patrimoni reial $i$ la recuperació dels senyorius jurisdiccionals en els estats catalanoaragonesos a la fi del segle XIV, "Anuario de Estudios Medievales", 7 (Barcelona, 1970$1971)$, pp. 351-451. Afirma aquesta autora que fou un fenomen generalitzat, especialment

"Anuario de Estudios Medievales", 28 (1998)
} 
mesures de sanejament dutes a terme pel rei Martí i continuades pels dos primers Trastàmara ${ }^{2}$.

En efecte, com afirma Christian Guilleré, és durant el regnat de Jaume II que es fonamentaren les estructures financeres de la Corona d'Aragó ${ }^{3}$. I, sens dubte, aquesta gestió encertada dels recursos reials per part del monarca anà aparellada del seu interès de recuperació de rendes, especialment després dels regnats d'uns monarques d'una liberalitat certament costosa per a la monarquia, com ho foren els dels reis Pere el Gran i Alfons el Franc, caracteritzats per unes fortes despeses exteriors i una reducció dels ingressos i del patrimoni reial. De fet, sabem que durant el regnat de Jaume el Just s'assumí, com a preocupació fiscal bàsica, la clarificació de la situació dels béns i drets de titularitat reial, i això de manera paral.lela, evidentment, a les actuacions adreçades a reforçar i afermar el poder reial per damunt de les diferents conflictivitats jurisdiccionals. Així, si les alienacions dutes a terme per Pere el Catòlic foren recuperades per Jaume I, les efectuades per Alfons el Franc ho seran per Jaume $\mathrm{II}^{4}$.

a partir del segle XIV, que les ben diversificades rendes ordinàries i extraordinàries del Patrimoni reial resultessin insuficients $\mathrm{i}$ inadequades per a les necessitats creixents dels estats; i que, per això, ben sovint el rei s'hagué de desprendre del capital de la Corona. Aquestes alienacions havien adquirit un ritme tan vertiginós durant els regnats de Pere el Cerimoniós i de Joan I que el Patromini reial restà exhaust, sobretot a causa de les empreses bèl-liques contra Gènova i Castella. Això menà que, a la fi del segle XIV, Martí l'Humà emprengués una política ben enèrgica de restauració del patromoni, la més àmplia programada fins aleshores, tant en la línia de recuperació dels béns alienats en els regnats anteriors com en el fet de declarar la inalienabilitat del Patrimoni reial. Tanmateix, cap a la fi del regnat de Martí I, de 1408 a 1410 , les dificultats inherents del mateix procés de redempció i les dificultats externes provocades per l'expedició a Sardenya obligaren no només a frenar el procés de lluïció, sinó a reprendre el camí de les alienacions dels béns patrimonials.

${ }^{2}$ Vegeu Manuel SÁNCHEZ MARTÍNEZ, Una aproximación a la estructura del dominio real en Cataluña a mediados del siglo XV: el "capbreu o memorial de les rendes e drets reyals" de 1440-1444, a "Estudios sobre renta, fiscalidad y finanzas en la Cataluña bajomedieval", Barcelona, Consejo Superior de Investigaciones Científicas, 1993, pp. 381453.

${ }^{3}$ Christian GuILleré, Les finances de la Couronne d'Aragon au début du XIV siècle (1300-1310), a "Estudios sobre renta, fiscalidad y finanzas en la Cataluña bajomedieval", Barcelona, Consejo Superior de Investigaciones Científicas, 1993, pp. 487-507. Cal veure també, dins aquest mateix volum miscel-lani, l'article de Flocel SABATÉ, Les castlanies $i$ la comissió reial de 1328, pp. 177-241.

${ }^{4}$ Christian Guilleré, Les finances de la Corona d'Aragó, "L’Avenç", 139 (Barcelona, juliol-agost, 1990), pp. 54-58. 
Un dels enclaus geogràfics on aquest fet de recuperació de senyorius jurisdiccionals, al final del segle XIII i començament del XIV, restà més palès fou precisament al que anomenem terres de l'Ebre, a les comarques més meridionals del Principat. I un dels poders feudals que n'esdevingueren protagonistes foren els templers, els quals havien convertit aquesta zona en el seu principal i més extens domini territorial de tota la corona catalanoaragonesa. Per tant, en aquest breu treball, dedicat a la memòria de qui fou sempre per a nosaltres un model insuperable de rigor i mètode històric, a més d'un exemple constant d'humanitat i dignitat personal, pretenem tan sols exemplificar aquest procés amb algunes mostres significatives i, principalment, amb la permuta de Tortosa realitzada pels templers amb el monarca Jaume II el setembre de $1294^{5}$.

Perquè cal recordar que dins aquest context $\mathrm{i}$, evidentment, com a resultat d'altres causes que s'hi sumaren en interacció i que analitzarem més endavant, en tractar de la permuta concreta que el Temple féu de la ciutat de Tortosa, coincidiren diferents reversions de dominis jurisdiccionals a la Corona. I que les més significatives foren protagonitzades precisament pels dos principals Ordes religiosomilitars d'abast internacional, el Temple i l'Hospital, a més d'altres senyorius laics, com ara els Montcada o els Entença.

En aquest sentit, cal tenir present, en primer terme, que el 7 de desembre de 1280 , de València estant, Pere el Gran permutà amb l'Orde de l'Hospital el castell i el terme d'Amposta pels llocs de Gallur i d'Onda. En efecte, atenent el tractat comú tingut entre el rei Pere, d'una banda, i fra Ramon de Ribelles, castellà d'Amposta, de l'altra, i considerant que aquest canvi anava en benefici de l'Orde, ja que els llocs que rebien eren, segons diu el document, més útils i de rendes més elevades, Galcerà de Timor, comanador de Sant Pere de Calanda i de Casp i lloctinent del castellà d'Amposta, amb l'assentiment de tots els comanadors de les cases de la Castellania, donava al rei Pere el castell i la vila d'Amposta, amb tots els seus homes, dominis i drets, amb inclusió dels llocs de la Ràpita, la Candela i l'Aldea i amb determinades retencions. A canvi, el monarca li lliurava el castell i la vila d'Onda, al regne

${ }^{5} \mathrm{El}$ marc general del que s'exposa en aquest article el trobareu desenvolupat en la nostra tesi Els templers de les terres de l'Ebre (Tortosa). De Jaume I fins a l'abolició de l'Orde (1213-1312), Tarragona, Diputació, 1999, 2 vols. 
de València, amb els seus termes i pertinences, i el castell de Gallur, amb l'heretat de Llop Eiximenis de Luna, al regne d'Aragó, amb tots els seus homes i rendes i amb la retenció exclusiva del peatge de Gallur i el mer imperi.

Amb aquest fet, el rei Pere II reforçava la seva posició al delta de l'Ebre, lloc privilegiat i estratègic, al bell mig de les tres unitats polítiques de la Corona, alhora que els frares hospitalers perdien el patrimoni del que havia estat la seva seu titular i de la qual en prenia el nom. El dia següent, el 8 de desembre de 1280 , Pere el Gran comunicà a Artal de Luna que havia encarregat al seu porter Alemany López de Jaca de donar possessió als hospitalers del castell de Gallur, i que havia advertit els habitants d'aquest lloc de la permuta realitzada. I avisà igualment els habitants d'Onda que havia encarregat al seu porter Ponç Sorel de donar-los possessió d'aquest $\operatorname{lloc}^{6}$. L'any 1298 el monarca Jaume II ratificà la permuta, bo i assenyalant els límits del terme d'Amposta?.

En segon lloc, pocs dies després del canvi amb l'Orde del Temple, el 7 d'octubre de 1294 Guillem de Montcada permutà també amb el rei Jaume II la ciutat de Tortosa, la Suda, el senyoriu, la seva tercera part de totes les rendes, com també la castlania, el domini i qualsevol altre dret que tingués a la ciutat de Tortosa i a la Suda i al castell de Paüls. En compensació d'això, el rei Jaume II li concedia els castells i les viles de Vallobar i de Saidí, a la línia fronterera entre Aragó i Catalunya, amb els seus cavallers, habitants, mer i mixt imperi, qualsevol altra jurisdicció, drets i pertinences, com també les cases, les heretats, les possessions i la jurisdicció que la Milícia del Temple tenia al lloc de

${ }^{6} \mathrm{AHN}$, OOMM, San Juan de Jerusalén, Castellanía de Amposta, Privilegios reales, carp. 585 , núm. 117 ; ACA, C, reg. 35 , fol. 172 , i AMT, calaix Castellania i Templers II, doc. 32 (trasllat d'11 d'octubre de 1406). Publicat per J. DelavilLE LE RoULX, Cartulaire général de l'Ordre des Hospitaliers de S. Jean de Jérusalem (1100-1310), Paris, Ernest Leroux, 1899, III, doc. 3.735, pp. 399-403. Vegeu José M. ${ }^{a}$ FONT RIUS, Cartas de población y franquicia de Cataluña, Madrid-Barcelona, Consejo Superior de Investigaciones Científicas, 1969, I-2, p. 785. Vegeu també Maria Mercè CosTA, Assaig cartográfic sobre la Catalunya de Jaume I, a "X Congreso de Historia de la Corona de Aragón", Zaragoza, Institución "Fernando el Católico", 1982, 3, 4 y 5, p. 465. I, especialment, Maria Bonet Donato, La Orden del Hospital en la Corona de Aragón. Poder y gobierno en la Castellanía de Amposta (ss. XII-XV), Madrid, Consejo Superior de Investigaciones Científicas, 1994, pp. 53-54.

${ }^{7}$ Enrique BAyERri Bertomeu, Historia de Tortosa y su comarca, Tortosa, Imprenta y Librería de Algueró y Baiges, 1957, VII, p. 643. 
Fraga i el seu terme. El document, signat per Guillem de Montcada i la seva muller, Beatriu, alhora que els refermava en el senyoriu de Fraga, significava la fi del domini senyorial dels Montcada sobre la ciutat de Tortosa, domini que s'havia establert arran de la conquesta cristiana i que ara era cedit en un marc certament diferent ${ }^{8}$.

Deu dies després, el 17 d'octubre, el batlle reial de Tortosa, Bernat de Llibià, rebia la procuració de Jaume II per prendre possessió del noble Guillem de Montcada del castell, de la Suda i de tots els drets que aquest tenia a la ciutat, en atenció a la permuta realitzada ${ }^{9}$. I el dia 19 del mateix mes el cavaller Ponç de Pau, procurador del noble Guillem de Montcada, senyor de Fraga, rebia del porter i procurador reial Miquel Violeta la possessió del castell i la vila de Saidí, amb tots els seus habitants, drets i pertinences i amb la jurisdicció plena, alhora que l'homenatge i el jurament dels homes d'aquest $1 \operatorname{loc}^{10}$.

Respecte d'aquest fet històric, Ramon Muntaner narra en el capítol CLXXVIII de la seva crònica: "Que a Tortosa havia durat bando gran entre los Garidells, e els Carbons e els Puigs; que per ço que ho pogués castigar, s'avenc (el rei Jaume II) ab En Guillem de Montcada, qui havia lo terç en Tortosa, e li'n donà canvi, e al Temple atretal. E, con tota la ciutat fo sua, adobà lo dit bando, qui per grat, qui per força, en tal manera que ara està pus pla que ciutat que sia en Catalunya" 11 . Evidentment, aquesta menció de la permuta de la ciutat, tant per part dels Montcada com del Temple, esdevé força senzilla i simplista, sobretot en restar emmarcada en el context de la pacificació del país per part del nou monarca Jaume II, i de posar fi a les bandositats i a les lluites internes entre les famílies tortosines principals. No obstant això, el mateix Ramon Muntaner no amaga la transcendència de Tortosa per a la política reial d'expansió per la Mediterrània, en parlar en diferents capítols de les drassanes, del port i de la mateixa ciutat en termes ben lloables ${ }^{12}$.

\footnotetext{
${ }^{8}$ ACA, C, reg. 194, fols. 79r.-81v., i AMT, calaix Privilegis III, doc. 17 (trasllat d'11 d'octubre de 1406)

${ }^{9} \mathrm{ACA}, \mathrm{C}$, pergamins de Jaume II, núm. 427, i ACA, C, reg. 194, fol. 82 r.

${ }^{10} \mathrm{ACA}, \mathrm{C}$, pergamins de Jaume II, núm. 428.

"Ferran Soldevila, Les quatre grans cròniques, Barcelona, Selecta, 1971, p. 827.

${ }^{12}$ Vegeu, per exemple, els capitols XXXVI i XLIV, sobre les drassanes; i els capitols XLVI, XLVIII, CXII, CCLXXIII i CCLXXVII, sobre el port, les galeres i les empreses reials d'expansió mediterrània.
} 
D'altra banda, uns anys després, però sempre dins la mateixa àrea geogràfica abans definida, el 3 de desembre de 1313 Jaume II comprava la baronia d'Entença per la quantitat de cent mil sous barcelonesos i vint mil sous de cens anual de per vida. D'aquesta manera es posava fi a una baronia, que inicialment abraçava els territoris de Móra, Tivissa, Garcia i Marsà, però que s'havia vist augmentada per compravendes i herències amb castells com els de Vandellòs i Falset. I això després de cent trentanou anys d'existència com a feu independent, en mans successivament dels Castellvell, Sobirats-Santmartí i Entença ${ }^{13}$.

Finalment, i aquest desitgem que esdevingui l'eix central del present article, el 15 de setembre de 1294, de la ciutat de Tortosa estant, fra Berenguer de Cardona, mestre provincial de l'Orde d'Aragó i Catalunya, permutava amb el mateix monarca Jaume el Just el domini templer sobre aquesta ciutat i el seu terme. A la capital de l'Ebre, els templers s'hi havien establert tot just després de la conquesta cristiana de 1148 , com a conseqüència directa de l'aliança d'aquest Orde amb la Corona i del seu compromís en la conquesta del país ${ }^{14}$. Confirmats en el seu senyoriu el 1175 per Alfons el Cast, pocs anys després, el 1182, assoliren el punt més àlgid en el domini de la ciutat, mercès a la donació de què foren objecte per part del mateix comte rei, domini que hagueren de compartir amb el casal de Montaca, tot i que sempre des d'una posició preeminent.

\section{LES CAUSES DIRECTES DE LA PERMUTA}

És evident que, ultra aquest marc general de recuperació de rendes i del patrimoni reial per part de la monarquia, tot un seguit de motius convergiren en un fet de tanta transcendència com fou la permuta que suposà la fi de la comanda de la capital de l'Ebre i del domini templer sobre el territori. En el mateix text de la permuta, el mestre provincial anotava des de bon començament, com a causa primordial, la

\footnotetext{
${ }^{13}$ Archivo Ducal de Medinaceli, Entença, lligall 1, doc. núm. 25. Vegeu Teresa PALET, Manuel ROMERo, Capbreu de la baronia d'Entença (s. XIV). Introduccuó històrica i estudi lingüístic, Tarragona, Excma. Diputació, 1987, p. 14.

${ }^{14}$ Laureà PAGAROLAS, La Comanda del Temple de Tortosa: primer periode (1148-1213), Tortosa, Cooperativa Gràfica Dertosense, 1984.
} 
impossibilitat de mantenir l'exercici ple de la jurisdicció sobre Tortosa i la mateixa disminució progressiva dels drets de l'Orde. Alhora, afegia la perspicaç observació que era preferible un canvi a temps a una retenció inútil del senyoriu, la qual no menaria sinó a la pèrdua total dels drets.

És evident que aquesta raó adduïda pel mestre provincial era més aviat la conseqüència de tot un seguit d'esdeveniments fets palesos des de mitjan segle XIII, el moment que marcà el punt d'inflexió en les relacions fins aleshores profitoses entre monarquia i Orde. D'una aliança inqüestionable, en uns temps d'expansió i enfortiment d'ambdues institucions, s'havia passat a una situació de recel. En efecte, des de mitjan segle XIII els privilegis i les prerrogatives dels templers comencen a minvar davant la pressió de dos elements aliats, la Corona i l'estament ciutadà, protagonista aquest del desvetllament urbà i comercial. Així, truncada l'expansió militar peninsular i disminuïts els ingressos davant la creixent burocratització i la necessitat de finançar les empreses de la Mediterrània, la Corona començà a reduir les atribucions fiscals i els privilegis de l'Orde. I, d'altra banda, la ciutadania lluità aferrissadament per la defensa dels seus drets i costums durant gairebé tot el segle XIII, en una pugna que esdevingué l'eix vertebrador de la vida política tortosina.

D'ençà de la dècada dels anys cinquanta de la tretzena centúria, el monarca no parà de requerir al comanador de Tortosa que complís amb els seus deures i que tributés de manera deguda als oficials reials. En aquesta línia, Jaume I no pretengué altra cosa que maximitzar el seu poder i, alhora, disminuir el domini templer sobre la ciutat. Aquest reforçament de l'autoritat del sobirà es féu palès en l'augment de les prerrogatives dels seus oficials, en el control del repartiment de les rendes senyorials, en el foment de la divisió entre els mateixos consenyors o en el suport donat a la causa ciutadana.

D'aquesta manera, des dels darrers decennis del regnat de Jaume I, augmentà el recel justificat dels templers, els quals, tot i mantenir el seu potencial econòmic, veien minvar les seves prerrogatives, alhora que el seu domini era qüestionat pels consenyors, combatut pels ciutadans i minat pel mateix sobirà. Ara, les lluites per rendes i jurisdiccions esdevingueren massa freqüents, i les pretensions del monarca toparen amb l'oposició de la senyoria del Temple, que pugnà per no veure com minvaven. La situació s'havia capgirat del tot i els mètodes d'actuació eren ben diferents. Ara eren els frares qui demanaven i pregaven i el monarca qui ordenava i consentia. I així es continuà durant els regnats de 
Pere el Gran i Alfons el Franc, que suposaren l'anorreament del règim senyorial, fins arribar finalment a la permuta de la ciutat de Tortosa el setembre de 1294.

Només a tall d'exemple d'aquest evident procés, apuntem les sentències que calgué dictar el 1261 i el 1263 sobre els litigis que els templers tortosins tenien plantejats amb els consenyors de la ciutat, els Montcada, els quals els anaven prenent terreny i s'apropiaven de prerrogatives i atribucions que no els eren pròpies. Com també, respecte de la Corona, recordem com el 1259 Jaume I pregava al comanador de Tortosa, aleshores fra Bernat d'Alta-riba, que respongués de tots els rèdits reials del lloc a Pere Ėnnec, batlle del monarca en aquesta ciutat. I com el 1271 el mestre provincial del Temple s'adreçava al noble Ramon de Montcada, bo i avisant-lo de les pretensions jurisdiccionals del rei sobre Tortosa, les quals, expressades en el fet de tenir batlle a la ciutat i cases a la Suda, prendre part en determinades imposicions o bé posseir facultats judicials, anaven en perjudici d'uns i altres.

En la mateixa línia, el 1276 l'infant Pere ordenava al comanador de la casa de Tortosa que no reclamés part dels rèdits provinents de la paeria de la ciutat, com ho havia fet, i que tributés degudament al batlle reial. És evident que el nou monarca no havia de permetre el més petit abús per part de l'Orde del Temple en el seu domini a la capital de l'Ebre. Així, el 1278 trobem Pere el Gran defensant ara els interessos dels Montcada, en manar al comanador de Tortosa que, si constava que Ramon de Montcada tenia dret sobre el monedatge de la ciutat, que es dividís i se li lliurés com era costum. I el 1279 ordenava al comandor de Tortosa que entregués al batlle reial la meitat del terç del monedatge, terç que els templers pretenien retenir per a ells de manera íntegra.

Finalment, tot el decenni dels vuitanta i l'inici dels noranta fou ple d'episodis que reflectiren el reforçament del poder reial i la disminució dels drets del Temple. Per exemple, el 1282 l'infant Alfons, ordenava a un oficial seu que exercís els drets de la vegueria i mer imperi a la ciutat i terme de Tortosa, bo i manant als senyors de la ciutat que no s'oposessin a aquesta disposició; el 1283 féu retornar els béns que el comanador de Tortosa havia pres en penyora a alguns sarraïns, per haverse traslladat a Amposta; el 1284 manà al preceptor templer que ajudés el col.lector del monedatge a cobrar aquest impost per la ciutat; el 1286 nomenà un jutge que entengués en la causa que hi havia entre els oficials reials d'Amposta i els senyors de Tortosa, respecte del dret de carnalatge 
d'aquell lloc; o el 1287 féu que el comanador de Tortosa lliurés al batlle reial els drets que corresponien a la batllia ${ }^{15}$.

D'altra banda, en aquesta mateixa direcció de disminució del poder i de la influència de l'Orde, cal afegir, en segon terme, la pròpia davallada interna del Temple. Perduts el 1291, amb la caiguda de Sant Joan d'Acre, els darrers bastions de Terra Santa, els seus objectius inicials de defensa dels Sants Llocs i de lluita contra els infidels restaren desvirtuats per complet, i els frares es veieren així mancats de finalitat $\mathrm{i}$, per tant, de justificació i de sentit. I això era més greu si considerem que comptaven amb unes estructures d'organització interna realment fortes. Les comandes havien esdevingut gairebé innecessàries, i és evident que la seva potencialitat econòmica havia despertat el recel de la monarquia, dels altres poders locals, com ara els Montcada, els hospitalers de la Castellania d'Amposta o la Mitra, i també del mateix poble, el qual, de vegades, fins i tot féu causa comuna amb els Montcada.

A més, cal afegir que els templers no han pogut o no han sabut adaptar-se, bo i cercant altres objectius que justifiquin el seu manteniment, a diferència per exemple de l'Orde de l'Hospital. Tot i la seva provada i excel.lent capacitat d'organització, els templers han demostrat una gran incapacitat d'articulació i d'inserció dins les noves estructures socials canviants, al segle XIII. I la ciutat de Tortosa, potser més que cap altra, ha estat un exemple ben clar d'aquests fenòmens. La forta pressió dels grups urbans, recolzats per la monarquia i de vegades també pels consenyors, menà la redacció dels Costums durant la dècada dels anys setanta. I, al capdavall, s'imposà el criteri resultant de la conjuntura històrica, i l'aprovació d'aquest codi es demostrà incompatible amb el mateix règim senyorial considerat.

Encara, hi havia una tercera raó de pes, expressada en el fet que les terres de l'Ebre havien esdevingut una zona estratègica, tant des del punt de vista econòmic com militar. Com afirma Cuvillier, fins a mitjan segle XIII el comerç del blat havia beneficiat de manera preferent ciutats com ara Barcelona, Montpeller o Perpinyà. Però, després dels trasbalsos polítics, econòmics i socials dels regnats de Pere el Gran i Alfons el Franc, la naturalesa del tràfic canvia i els corrents comercials es

\footnotetext{
${ }^{15}$ Vegeu, sobre aquest aspecte, el capítol quart del nostre treball Els templers de les terres de l'Ebre, dedicat a l'evolució del règim senyorial tortosí.
} 
desplacen. Les regions meridionals -el delta de l'Ebre i el regne de València - entren així en l'àrea cerealista catalanoaragonesa, de manera que, pràcticament fins al segle XVII, Tortosa actua com a sortida al mar del regne d'Aragó i controla el trànsit dels grans aragonesos en direcció a Catalunya. Sens dubte, l'economia de les regions de llevant es reactiva i l'Ebre adquireix un paper nou. La monarquia, assolida l'etapa de conquesta peninsular, se centrà en l'assimilació i l'explotació de les conquestes, i la ciutat de Tortosa simbolitzà, atesa la seva prosperitat creixent, l'ingrés de les regions meridionals de la Corona d'Aragó en el comerç mediterrani ${ }^{16}$.

I, reblant aquest interès econòmic de la monarquia per la zona del delta, cal considerar també els atractius de tipus militar, perquè és prou conegut com Tortosa esdevé per a la Corona una plataforma important de la seva política d'expansió per la Mediterrània, especialment després de la intervenció de Pere el Gran a Sicília. D'altra banda, a més d'actuar d'arsenal i de punt clau en la política militar de la Corona, cal afegir que Jaume II comprengué prou bé els interessos del delta de l'Ebre, i el cert és que Tortosa finança en certa manera la política naval de la monarquia. La tresoreria reial descobreix les possibilitats que ofereixen les fortunes burgeses de la vila, i la ciutat, que juga com altres la carta de la fidelitat monàrquica, comença a rebre privilegis i franqueses.

En síntesi, es podria afirmar que Jaume el Just entengué que calia reforçar el paper de la monarquia, restringint el camp d'acció dels poders senyorials, i això d'una manera especial a la zona de les terres de l'Ebre, on tenia uns interessos econòmics i militars clars. Per fer-ho, aprofità el moment de crisi dels Ordes religiosomilitars, mancats d'objectius i de capacitat d'atracció i d'inserció social, i reduïts a unes estructures gairebé obsoletes, d'altra banda econòmicament i políticament encara fortes i que, per tant, calia bandejar.

\footnotetext{
${ }^{16}$ Jean Pierre CUVILLIER, La noblesse catalane et le commerce des blés aragonais au début du XIVè. siècle (1316-1318), "Melanges de la Casa de Velázquez" (Paris), VI (1970), pp. 113-130.
} 


\section{El CONTINGUt I L'ABAST DEL CANVI}

Considerades les causes exposades en els capítols anteriors, la permuta de la ciutat de Tortosa esdevingué un tema que preocupava les dignitats templeres del país. De fet, sabem que en el concili provincial de l'Orde celebrat a Montpeller l'estiu de 1293, ja es parlà del canvi del senyoriu i que la proposta fou acceptada ${ }^{17}$. I cal pensar que igualment es féu en el capítol provincial de Gardeny de maig de 1294. Per això, és lògic que l'agost d'aquest any trobem el mestre provincial, fra Berenguer de Cardona, a Lleida tractant la qüestió amb el gran mestre, Jaume de Molay, i altres dignitats de l'Orde ${ }^{18}$. Un cop presa la decisió, el 27 d'agost de 1294, de Lleida estant, el gran mestre Jaume de Molay, de consell de diferents comanadors i altres membres del seu seguici personal concedia a fra Berenguer de Cardona potestat plena per realitzar la permuta de la ciutat i terme de Tortosa, bo i presentant com a garantia els béns de l'Orde ${ }^{19}$.

Poc després de feta la procuració, el 15 de setembre de 1294, es redactava el document de la permuta, amb les sol.lemnitats formals acostumades i que constava, bàsicament, de dues parts, la de l'Orde i la del rei $^{20}$. Així, en primer terme, el mestre provincial cedia al monarca la ciutat de Tortosa, amb la Suda, les fortaleses, els cavallers i els habitants, el domini i la jurisdicció, el mer i mixt imperi, com també tots els drets que es detallaven puntualment a continuació, que posseïen d'acord amb la donació reial de 1182 feta per Alfons el Cast. Es feia esment especial del cens anual dels sarraïns per les obres a les muralles i la Suda; del cinquè de les rendes que els pertocava segons la donació de 1143 , i dels banys que els templers tenien a l'Alfòndec.

Després d'un seguit de fórmules usuals en aquests tipus documentals, de fermança, seguretat i obligació de jurament al nou senyor,

\footnotetext{
${ }^{17}$ Francesch CARRERAS Y CANDI, Entences y templers en les montanyes de Prades (1279 á 1300), a "Miscelanea Histórica Catalana", Barcelona, Imprenta de la Casa Provincial de Caridad, 1905, I, pp. 241-243.

${ }^{18}$ Alan J. FOREY, The Templars in the Corona de Aragón, London, Oxford University Press, 1973, p. 317.

${ }^{19}$ Publicat per Laureà PAgarolas I SABATÉ, Els templers de les terres de l'Ebre, II, doc. 171 .

${ }^{20}$ Ibidem, doc. 172.
} 
s'indicaven les retencions generals fetes per l'Orde, enteses com a heretats pròpies del Temple, sense determinar, ja que això es recollia en un altre document de 21 de setembre del mateix any, del qual es feia esment en el text. De fet, no ha d'estranyar la menció d'un document atorgat sis dies després, perquè creiem que cal pensar en una redacció simultània dels instruments, i en una signatura solemne posterior de les diferents cartes de retencions de drets per part dels frares.

I a continuació es detallaven els castells, viles i llocs rebuts a canvi pels templers: el castell i la vila de Peníscola, amb les seves aldees de Benicarló i Vinaròs; el castell i la vila d'Ares; tota la tinença de les Coves de Vinromà, és a dir, els castells i les viles de Coves, Salsadella, Albocàsser, Vilanova, la Serra i Tirijà; tot el domini reial sobre el castell i els homes d'Ollers, a la Conca de Barberà, i finalment totes les cenes de la batllia de Xivert.

En segon terme, el monarca Jaume II rebia la ciutat de Tortosa i la permutava pels llocs i viles esmentats. I, tot seguit, s'iniciava una minuciosa anotació dels límits dels llocs rebuts pels frares i cedits pel rei. A continuació, el sobirà abundava en l'abast de la seva donació, que incloïa igualment béns, persones i drets, amb especial menció de la sal i la gabella de Peníscola, el seu port i els mercats de Peníscola i Albocàsser, per cloure finalment amb semblants clàusules que la part anterior. És evident que aquesta permuta era ben desfavorable per als interessos dels frares, els quals cedien el control sobre un dels centres neuràlgics de la Corona $\mathrm{i}$ on havien desplegat un dels seus primers dominis senyorials. La pèrdua dels drets sobre la rica ciutat comercial tortosina i sobre tot el territori es veié pobrament compensada per dominis a la Plana i al Maestrat, al nord del regne de València.

Aquestes terres, conquerides per Jaume I i que havien passat després al noble Blasc d'Alagó, foren repoblades en la mateixa segona meitat de la tretzena centúria. I la seva riquesa, fonamentada en una base agropecuària, mai no es podria comparar a la ciutat de Tortosa $\mathrm{i}$ als castells i les viles de les ribes de l'Ebre, on, a més d'unes rendes elevades, gaudien de tota mena de drets senyorials. Només el castell i la vila de Peníscola podien oferir un cert atractiu, mercès al seu emplaçament estratègic, a l'existència del port, a la seva riquesa salina i al cobrament del corresponent impost de la gabella de la sal.

Redactat el document principal de la permuta el 15 de setembre i signats els textos sobre les retencions templeres el 21, el 24 de setembre 
es daten un seguit d'instruments de procuracions i de presa de possessió dels llocs permutats, tal com era preceptiu en canvis de dominis senyorials. Així, en primer lloc, el mestre fra Berenguer de Cardona, nomena procurador seu el comanador d'Ascó, fra Arnau de Torrella, i l'autoritza per donar possessió al monarca de la ciutat de Tortosa, alhora que mana als habitants d'aquesta ciutat que retin homenatge al nou senyor ${ }^{21}$

Aquesta possessió de Tortosa fou presa pels procuradors reials nomenats el dia 30 del mateix mes, Bernat de Sarrià i Pere de Llibià, aquest darrer batlle general del regne de València ${ }^{22}$. I, seguint els preceptes indicats en la procuració templera, el 17 d'octubre els síndics de la universitat de Tortosa, en nom propi i del municipi, feren homenatge al nou senyor, el monarca Jaume II. Els representants municipals eren, com és ben lògic, els membres de les més significatives famílies de la Tortosa del segle XIII: Berenguer Pinyol, Ferrer de Bas, Pere Jordà, Ramon Calderer, Berenguer Garidell, Pere Carbó, Bernat Garidell, Guillem Solsona, Bernat de Vilalbí, Ramon Tomàs, Llorenç Cima i Lluquet Cuceller ${ }^{23}$.

D'altra banda, les procuracions i presa de possessió dels castells $\mathrm{i}$ les viles cedits pel monarca es feren de manera individual, amb documents particulars per a cadascun, el mateix 24 de setembre. Així, el procurador nomenat per Jaume II per donar possessió al mestre provincial de la vila de Peníscola i les seves aldees fou Guillem de Ceret ${ }^{24}$; el dels castells d'Ares i Coves de Vinromà fou Esteve de Seta, porter reial ${ }^{25}$, i, finalment, el del castell d'Ollers, a la Conca de Barberà, fou Bernat de Canelles, veguer reial de Vilafranca i Montblanc ${ }^{26}$. Tots aquests textos

\footnotetext{
${ }^{21}$ Ibidem, doc. 175 .

${ }^{22}$ Ibidem, doc. 179 .

${ }^{23} \mathrm{ACA}, \mathrm{C}$, reg. 194, fol. 77v.

${ }^{24}$ Publicat per Laureà PAGAROLAS I SABATÉ, Els templers de les terres de l'Ebre, II, doc. 176.

${ }^{25}(25)$ Ibidem, doc. 177.

${ }^{26} \mathrm{ACA}, \mathrm{C}$, reg. 194 , fol. $75 \mathrm{v}$.
} 
s'acompanyaven igualment del manament adreçat als habitants de retre homenatge al nou senyor ${ }^{27}$.

La possessió d'aquests antics llocs reials fou també presa pel mestre provincial del Temple mitjançant documents individuals, com a exemple dels quals tenim el referit a Ares i Coves de Vinromà. Redactat el dia 30 de setembre, fra Berenguer de Cardona hi reconeixia que el ja esmentat Esteve de Seta havia lliurat aquests llocs al comanador de Cantavella, fra Eiximenis de Lenda, el qual actuava en nom seu ${ }^{28}$. Sens dubte, documents similars es redactaren respecte dels altres castells permutats, inserits tots ells en el conjunt de la paperassa obligatòriament generada al voltant de l'atorgament d'un text tan cabdal com era la permuta d'un senyoriu jurisdiccional.

\section{LES RETENCIONS POSTERIORS}

La signatura del document de permuta de la ciutat de Tortosa suposà el punt final de la participació del Temple en les estructures de poder de la ciutat $i$, al capdavall, del règim senyorial de l'Orde a la zona del baix Ebre. No obstant això, tal i com es deia en el mateix text, pocs dies després es firmaren tot un seguit d'instruments annexos, relatius a determinades retencions i reserves de domini per part dels frares, com també al salvament de certs drets territorials $\mathrm{i}$ jurisdiccionals, als manaments de delimitacions dels territoris permutats o a les ordres reials de fer respectar les franqueses i immunitats.

Tot i que alguns els suposem escrits simultàniament al de la permuta, la majoria d'aquests textos foren completats i signats sis dies després, és a dir, el 21 de setembre de 1294. I, com de fet tenim documentat, en els anys immediatament posteriors havien d'esdevenir

\footnotetext{
${ }^{27} \mathrm{Cal}$ afegir que aquest manament de retre homenatge als frares del Temple, en qualitat de nous senyors del lloc, fou adreçat pel monarca als municipis respectius de manera directa. Vegeu, per exemple, ACA, C, reg. 194, fol. 75r.-v., on es documenta, respecte del lloc d'Ollers, el manament reial fet el mateix 24 de setembre als homes d'aquest indret de retre homenarge al mestre provincial, al seu procurador o, en tot cas, al comanador de Barberà. Aquest text s'acompanya d'altres assentaments que indiquen que cartes similars s'havien adreçat als homes de Peníscola, d'Ares i de les Coves de Vinromà.

${ }^{28}$ Publicat per Laureà PAGAROLAS I SABATÉ, Els templers de les terres de l'Ebre, II, doc. 178
} 
origen de litigis i conflictes, d'una manera especial amb l'estament dels ciutadans de Tortosa, els quals ben poc havien de respectar el seu contingut, ja que lesionava els seus interessos, per exemple en el vessant dels prats i les pastures als llocs de Prat i Burjassénia.

Sens dubte, el més important d'aquests documents és el citat en el mateix text de la permuta $\mathrm{i}$ que no vàrem incloure en la col.lecció documental de la nostra tesi, tot i ressenyar-lo. Atesa la seva riquesa i les possibilitats enormes d'aprofitament que ofereix, el transcrivim de manera íntegra en apèndix, per bé que no entrarem a fons en el seu contingut, perquè aquest és precisament l'objecte d'anàlisi de l'article de Joan Fuguet inserit en aquest mateix volum miscel.lani, sobre fortificacions menors i altre patrimoni retingut pels templers a Tortosa després de 1294.

En síntesi, es tracta del reconeixement que fa el rei Jaume II de les retencions efectuades per l'Orde com a heretat pròpia, exclusivament a la ciutat de Tortosa i al seu terme estricte. Com podem comprovar en llegir-lo, el text és molt puntual, detallat i minuciós, ja que descriu, fil per randa, totes les fortaleses, cases, corrals, solars urbans, patis, forns, terres, camps, oliverars, vinyes, horts, rèdits i censals, "in quibus dominacio comunis Dertusa non habet vel accipit partem" i, per tant, exclosos de la permuta $i$ retinguts pels frares. La ingent quantitat $i$ diversitat de les propietats reservades palesa la riquesa i el poder dels templers a la Tortosa del segle.

Fàcilment podem adonar-nos que, dins el tramat urbà, els frares posseïen importants propietats en cases, patis i solars a punts ben diversos, com ara: als eixos d'expansió urbana medieval que constituïen el Coll de Sant Joan i la mateixa casa convent del Temple; dins el clos murallat romà, al carrer dels Garidells; al nou barri de l'església de Sant Nicolau i de Remolins, i també a la zona del convent de Santa Clara. Com ja els coneixíem igualment les seves propietats rústiques més importants, esteses sobretot a les fèrtils ribes de l'Ebre, tant a la dreta com a l'esquerra. Destaquem, com a més notables i en l'ordre d'aparició al text, Bercat, Arenys, Giramascor, Benigeral, Pimpí, Palomera, Bítem, Labar, Mianes, Benifallet, Xerta i, especialment, el conjunt format per Burjassénia, Prat i Quint, on recordem que arribaren a organitzar una sotspreceptoria i reserva que esdevingué potser el principal punt de conflicte amb els ciutadans de Tortosa. 
A més d'aquest document puntual de retencions, certament interessant, se'n redactà un segon, de caire més general, de reconeixement per part del monarca d'un seguit de privilegis i immunitats fets als frares sobre el domini tortosí que ara deixaven, com per exemple: el dret de lliure pastura; l'exempció quant al pont i la barca de Tortosa i Benifallet; l'afranquiment dels drets de lleuda, peatge, pes i mesura, herbatge i carnalatge; la immunitat dels frares davant el veguer i els oficials del rei i dels Montcada, en els termes de Miravet i Horta, tal com era costum; la confirmació dels antics privilegis de l'Orde i, en general, la protecció reial d'homes i béns dels frares del Temple ${ }^{29}$.

Encara, mitjançant un tercer instrument, les dues parts implicades en la permuta s'absolien de manera recíproca, respecte de l'obligació mútua de lliurar-se la meitat dels béns adquirits per donació, compra, almoina, llegat o qualsevol altre títol, d'acord amb els pactes signats pels seus predecessors, com també de tots els drets sobre la ciutat i la batllia de Tortosa $^{30}$. La força d'aquests documents es veié reblada pel manament de Jaume II, el 24 de setembre, al veguer, al batlle i als prohoms de Tortosa de respectar $\mathrm{i}$ fer complir les franqueses i immunitats concedides al Temple tres dies abans ${ }^{31}$.

Per acabar, afegim que un altre grup de documents paral.lels a la permuta foren els relatius a les delimitacions dels territoris, redactats amb una finalitat doble: determinar què corresponia a cada jurisdicció i, alhora, esclarir els possibles enfrontaments que poguessin sorgir en el futur. Així, el mateix 21 de setembre Jaume II reconeixia que els templers es reservaven el terme de Montsagre, entre Horta i Paüls, i a continuació afegia que delimitaria amb fites el terme de Tortosa, en

\footnotetext{
${ }^{29}$ Ibidem, doc. 173. Aquest reconeixement reial anà acompanyat d'altres privilegis del monarca, en què concedia determinats beneficis $i$ franqueses als templers sobre els llocs permutats, al regne de València. Per exemple, sobre la llibertat de comerciar amb Peníscola, de comprar sal i de cobrar la lleuda i la gabella d'aquest lloc (ACA, C pergamins de Jaume II, núm. 395, i ACA, C, reg. 194, fols. 69v.-70v.). O sobre el manament reial als seus oficials de no cobrar ni exigir determinats drets als templers en els nous assentaments (ACA, C, pergamins de Jaume II, núm. 400).

${ }^{30}$ Publicat per Laureà PAGAROLAS I SABATÉ, Els templers de les terres de l'Ebre, II, doc. 174.

${ }^{31} \mathrm{ACA}, \mathrm{C}$, reg. 194, fol. $74 \mathrm{v}$. Semblantment és ordenat als oficials reials en els assentaments següents.
} 
prendre possessió de la ciutat, per separar-lo dels termes de Miravet i Horta, que continuaven essent del Temple, i evitar futures dissensions ${ }^{32}$.

Tot i les importants retencions conservades després de la permuta, sabem que la comanda periclità ràpidament com a tal. La documentació d'aquests anys reflecteix només l'actuació isolada del comanador i d'un sol frare, encarregats un i altre de dur a terme una funció de manteniment i de vetllar per les rendes derivades de les reserves. Prodríem dir que la casa de Tortosa s'estalvià, d'aquesta manera, els trasbalsos dels anys difícils, des de l'octubre de 1307, amb l'empresonament dels frares de França, fins al març de 1312, amb l'abolició de l'Orde.

${ }^{32}$ ACA, C, pergamins de Jaume II, núm. 394; ACA, C, reg. 194, fols. 66r.-68r., i AHN, OOMM, San Juan de Jerusalén, Castellanía de Amposta, Bailia de Miravete, carp. 609 , docs. 66 i 69 . Uns dies abans, el 10 de setembre, la universitat de Tortosa havia nomenat Ferrer de Bas i Ramon Calderer procuradors per actuar en la divisió de termes (AHN, OOMM, San Juan de Jerusalén, Castellanía de Amposta, Bailía de Miravete, carp. 609, doc. 64). I, encara, el 25 d'agost de 1294, per tant abans de la permuta, es fixaren les confrontacions de les noves possessions templeres, amb la intervenció, entre d'altres, del batlle general del regne de València, Bernat de Llibià, per la part reial, i del comanador d'Ascó, fra Arnau de Torrella, per l'Orde (ACA, C, pergamins de Jaume II, núm. 392). 


\section{APÈNDIX DOCUMENTAL}

1294, setembre, 21. Tortosa

El monarca Jaume II reconeix, de manera precisa i detallada, a fra Berenguer de Cardona, mestre del Temple d'Aragó i Catalunya, tots els drets i totes les possessions, tant urbanes com rústiques, que l'Orde del Temple s'ha retingut a la ciutat i terme de Tortosa, després de la permuta signada entre ells sis dies abans.

ACA, C, reg. 194, fols. $63 \mathrm{v} .-66 \mathrm{r}$.

In Christi nomine. Sit omnibus manifestum quod nos, Iacobus, Dei gracia rex Aragonum, Sicilie, Maioricarum et Valencie ac comes Barchinone, cum testimonio huius publici instrumenti, confitemur et recognoscimus in veritate vobis, venerabili ffratri Berengario de Cardona, magistro domorum Milicie Templi in Aragonia et Cathalonia, quod in concambio et permutacione quam nobiscum fecistis de civitate Dertuse pro castris et villa de Paniscola et de Ares et pro tota tenencia de Covis de Avinromano et de quibusdam aliis, prout in instrumento publico inde inter nos facto super ipso concambio per notarium infrascriptum XVII ${ }^{\circ}$ kalendas octobris, anno Domini $\mathrm{M}^{\circ} \mathrm{CC}^{\circ} \mathrm{CX}^{\mathrm{o}}$ quarto plenius continetur, retinuistis vobis et fratribus Templi perpetuo in civitate et terminis Dertuse hereditates proprias Templi, scilicet, turres, boverias, honores, olivaria, domos, corrales, furnos, campos, vineas, ortos, terras et quascumque alias possessiones ac redditus et censsualia que vos et fratres dicte Milicie habetis et possidetis in dicta civitate Dertuse et terminis suis, in quibus dominacio comunis Dertuse non habet vel accipit partem, prout inferius sunt scripta et notata, videlicet, domos cum turri que vocatur lo Corral, que sunt in civitate Dertuse predicta. Item, totum censsuale sexaginta duarum mazmutinarum et centum octuaginta unius solidorum et sex denariorum censualium iaccensium, quod vos et dicta Milicia Templi habetis et accipitis in diversis hospiciis, domibus, patuis et edeficiis sitis in dicta civitate infra portale collis de Sancto Iohanne, intus et extra, usque ad domos sive corrale dicte Milicie Templi, et de 
orta episcopi usque ad vicum d'en Iovals, et usque ad vicum Dominici Deu. Item, quendam furnum situm infra affrontaciones predictas. Item, duas domos contiguas dicto corrali. Item, tres patis sive spacia domorum, que sunt infra affrontaciones predictas, quorum unum // (64r.) confrontatur ex tribus partibu's in viis publicis et ex alia parte in domibus Michaelis de Castilione, et aliud affrontatur cum domibus d'en Vidrier et cum orto episcopi et cenia balneorum; et aliud confrontatur cum cenia balenorum et orto episcopi, in via publica et domibus Raimundi Franch. Item, duas domos affrontantes cum caldaria balneorum et in viis publicis. Item, tres patis sive solars domorum iuxta ceniam balneorum. Item, quasdam domos que sunt in vico dels Garidels, quas Raimundus Sahuc tenet ad censum pro dicta Milicia. Item, quasdam domos sitas iuxta ecclesiam Sancti Nicholay, quas tenet Dominicus Garçia. Item, quasdam domos que sunt in dicta civitate, in loco vocato Remolins, quas tenet Dominicus de Oscha ad censum pro dicta Milicia. Item, ibidem quandam domum quam tenet Nicholava, uxor quondam d'en Licer. Item, ibidem aliam domum quam tenet Raimundus Fferrarii pro dicta Milicia. Item, ibidem quasdam domos quas tenet na Cerdana. Item, quandam domum quam tenet ibidem Guillelma de Alcover. Item, ibidem quandam aliam domum quam tenet Petrus Februaris et quandam aliam domum quam tenet ibidem Iohannes de Carmenço et quasdam domos dirutas que fuerunt Dominici Nicholay. Item, ibidem quasdam domos quas tenet Dominicus del Corral. Item, ibidem quasdam domos quas tenet Berengarius Alcherii. Item, ibidem quandam domum que fuit de na Carcassona. Item, ibidem quasdam domos quas tenet Marcho Pena. Item, quoddam patium quod tenet Bernardus Ortolani, et aliud patium quod consueverat tenere quidam qui vocabatur Simeo. Item, ibidem quandam domum quam tenet quadam mulier vocata Narbona. Item, quasdam domos dirutas que sunt intus Remolins et fuerunt Mathei de Calaceyt. Item, quoddam patium in loco vocato ${ }^{a}$ Remolins Barrani affrontatum in viis publicis. Item, quodam aliud patium quod tenet Bernardus Ortolani. Item, quandam domum in vico Ianuensium, quam tenet pro dicta Milicia Vives Iorneti. Item, quasdam domos quas tenet pro eadem Milicia iuxta pontem Petrus Alegre. Item, quasdam domos que fuerunt quondam Dominici Peu, iuxta monasterium sororum minorum. Item, quảsdam domos iuxta populacionem de Montecathano, quas tenet Bernardus de Balagerio. Item, quendam mansum seu turrim vocatam Barcat, cum vinea, olivariiis et pertinenciis suis. Item, quatuor vineis in loco vocato Arenes, quarum unam tenet Arnaldus Cathalani, et alteram Romeus Aguiloni, et aliam Bernardus Castilionis ad certum tempus pro ipsa Milicia, et aliam tenet dicta Milicia ad suam dominicaturam. Item, quandam turrim sitam iuxta civitatem Dertuse, cum orto, hereditatibus et possessionibus, terris et laboracionibus suis. Item, quatuor sortes vinearum in campo seu loco vocato Escorxalbous, que tenentur ad certum censum ${ }^{b}$ pro dicta Milicia. Item, undecim sortes vinearum // (64v.) in loco vocato lo Canar, que 
tenentur ad certum censum pro dicta Milicia. Item, duodecim sortes vinearum, que sunt in loco vocato Giramascor, iuxta flumen Iberis, que tenentur pro dicta Milicia. Item, sexdecim sortes vinearum in loco vocato Giramascor, iuxta iter quo itur usque Valencia, que tenentur pro dicta Milicia ad certum censum. Item, quendam ortum quem tenet Guillelmus de Sancto Clemente pro dicta Milicia. Item, quandam peciam seu sortem terre quam tenet Bernardus Iuneda ad certum censum. Item, quendam campum in loco vocato Benigerau, qui tenetur pro dicta Milicia. Item, quoddam pratum iuxta locum vocatum Escorxalbous, et quendam campum in loco vocato Amareyna, et quendam alium campum in loco vocato Benigerau. Item, duas pecias seu sortes terre in loco vocato Castelnou. Item, quandam vineam in loco vocato Camp del Caval. Item, quendam campum in loco vocato Castelnou, quem tenet pro dicta Milicia Bernardus Cahors. Item, quandam peciam terre in loco vocato Palomera, quam tenet Bernardus Michel. Item, quasdam vineas que sunt in montanea vocata la Polella, quas tenent pro dicta Milicia ad censum Guillelmus Bertrandi et Arnaldus de Reus et na Bitema. Item, duas pecias terre in loco vocato Castelnou, quas tenent pro dicta Milicia en Pabia et en Palau. Item, novem sortes terre ${ }^{c}$, inter vineas, ortos et campos, in loco vocato la Remula, subtus locum vocatum Pimpi, que tenentur pro dicta Milicia Templi. Item, quoddam olivare et quandam vineam in podio de Pimpi, quam hodierna d'en Sanz ad certum censum tenet pro dicta Milicia. Item, duas pecias terre in loco vocato Palomera, quas tenet pro dicta Milicia Bernardus Figuerola ad certum censum. Item, tres ortos et quoddam olivare in loco de Pimpi, que tenentur pro dicta Milicia a diversis personis. Item, quoddam olivare iuxta carreriam de Bitem, quod tenet Ffalchu Mambro, sarracenus, pro dicta Milicia ad certum censum olei. Item, quoddam aliud olivare in loco vocato Mollet, quod tenet Barberana de Podio pro dicta Milicia. Item, quoddam aliud olivare iuxta ortum Mathei de Muntblanch, quod tenetur pro dicta Milicia. Item, quandam vineam cum olivari in montanea, quam tenet Arnaldus Fferrarii pro dicta Milicia ad certum censum. Item, quinque sortes terre in loco vocato Labar, quas tenet Dominicus Poblador. Item, duas sortes quas dicta Milicia habet in quodam olivare quod est iuxta mansum Astrugi Sexoni, quondam. Item, quendam mansum cum orto ${ }^{d}$ et duobus olivaribus que tenet hodie na Avarneda. Item, castrum seu locum vocatum Burgazenia, cum suis honoribus, possessionibus, hereditatibus, devesiis, terminis et pertinenciis universis. Item, turrim seu // (65r) domum vocatam lo Prat, cum terris, honoribus, possessionibus, olivaribus, pratis, devesiis et aliis suis pertinenciis universis. Item, quendam locum vocatum Quinto, cum honoribus et possessionibus, terris, pratis et terminis ac suis pertinenciis universis. Item, quoddam pratum vocatum Aguilo, ubi olim consuevit esse mansus Petri Cucuphatis. Item, quendam mansum vocatum Mianes, cum campis, honoribus, possessionibus, terris, pratis, garrigiis, devesiis ${ }^{e}$, vineis, orto et suis pertinenciis universis. Item, quendam 
honorem qui fuit Petri Cintiliis in loco vocato de Aldovesta, que tenet Ubaquer Almuller ad certum censum $f$ pro dicta Milicia. Item, ibidem quendam alium honorem quem dictum Ubaquer ibi tenet ad certum censum. Item, ibidem quendam honorem qui fuit d'en Centeyles et d'en Savasona, quem $\mathrm{Ali}^{8}$, filius Alcaydi, et mater sua tenent ad certum censum pro dicta Milicia. Item, ibidem alium honorem qui fuit Bernardi d'en Abaz, quem idem Ali et mater sua tenent pro dicta Milicia. Item, quoddam patuum sive solar terre in loco vocato Tiveng, quod tenet pro dicta Milicia Mahomet Capdauri ad certum censum. Item, ibidem quoddam olivare in loco vocato Çarroc. Item, ibidem aliud olivare in loco vocato la Bassa. Item, aliud olivare in Benifaleto, in loco vocato lo domenge del Camp. Item, in Benifaleto duas dominicaturas quas tenet pro dicta Milicia Mufferrig Alaminus, quarum altera est in loco vocato Laiuçalmedina, et altera in loco vocato Çalicaba. Item, quoddam aliud olivare in dicto loco de Benifaleto quod vocatur lo domenge de Carcasona. Item, quintam partem quam dicta Milicia habet in honore de na Bonafos, sito in dicto loco de Benifaleto, et quandam olivariam in honorem d'en Moravig, et quandam aliam olivariam in loco vocato Torres, et duas olivarias in campo vocato del Camp, et tres olivarias in campo predicto, quod tenet en Moravig. Item censum unius canteri olei quem sarraceni archiepiscopi morantes in Benifaleto faciunt dicte Milicie annuatim. Item, quandam peciam terre in loco vocato Almedilla, quam tenet Almufferig Alaminus pro dicta Milicia ad certam partem fructuum. Item, quandam aliam peciam terre in loco vocato Çalicaba, quam idem Mufferrig tenet ad certam partem fructuum pro dicta Milicia. Item, quandam peciam terre in loco vocato Alguiçira, quam dictus Mufferrig tenet pro dicta Milicia ad certam partem fructuum. Item, quandam vineam et olivare et figeral in dicto // $(65 \mathrm{v}$.$) loco$ de Benifaleto, quam Alaminus de Benifaleto tenet ad certum censum pro dicta Milicia. Item, quoddam olivare vocatum Cugul in loco vocato Xerta. Item, ibidem quoddam aliud olivare vocatum Cugul, quod tenet Navinacava. Item, ibidem quendam campum heremum iuxta iter quo itur verssus Ortam. Item, ibidem quoddam olivare in loco vocato Cacau, quod tenet Petrus Pelicer ad certam partem fructuum. Item, ibidem in loco vocato Pedregal quoddam aliud olivare, quod tenet Petrus Pelicer pro dicta Milicia. Item, quendam campum et duodecim olivars in dicto loco de Xerta, in diversis locis, que tenet Guillelmus Pelicer pro dicta Milicia Templi ad certam partem fructuum. Item, ibidem medietatem quam dicta Milicia habet in Algezira, quam tenet Iacobus Bacuch. Item, ibidem quoddam aliud olivare in loco vocato Trehit, quod tenet Yzamagar de Tiveng ad certam partem fructuum. Item, ibidem quandam vineam in loco vocato l'Argilagar, quam tenet Paschasius Borracii ad certam partem fructuum pro dicta Milicia. Item, ibidem in eodem loco quandam vineam quam tenet en Camus. Item, ibidem quendam honorem in loco vocato Madrona, quem tenet na Orana ad certam partem fructuum. Item, ibidem quoddam molendinum drapium 
quod tenet Iohannes Boxados pro dicta Milicia et pro monasterio Sanctarum Crucum. Item, ibidem quoddam olivare in loco vocato Aldeyes, quod dicta Orana tenet ad certam partem fructuum. Item, ibidem quandam vineam in valle que dicitur ${ }^{h}$ d'en Azmet Ros, quam tenet Vincencius d'Arnes ad certum censum. Item, ibidem quoddam olivare in loco vocato Pedregal, quod tenet Bernardus Camus ad certum censum. Item, quendam ortum quem tenet Pascasius Borraz ad certum censum. Item, ibidem quendam honorem quem tenebat pro dicta Milicia Mahomet Abagelut. Item, quoddam olivare quod est in loco vocato Ligem. Predicta siquidem omnia et singula superius nominata et per vos, dictum magistrum, retenta, volumus et concedimus quod vos et alii fratres Templi in perpetuum habeatis, teneatis, possideatis et expletetis, franche, libere et quiete et absque omni honere servitutis et vicinatici, prout ea hodie melius habetis et possidetis et actenus melius habere et tenere consuevistis, promitentes ac eciam concedentes vobis et aliis fratribus Templi quod vos vel domina regina, fratres, filii ac procuratores seu alii officiales ac successores nostri in predictis vobis retentis non exhigemus, recipiemus vel // (66r.) exigi ac recipi faciemus cenas, albergas, ademprivia, servicia seu aliquam aliam exaccionem regalem. Et nichilominus per nos et nostros promitimus vobis quod predicta omnia et singula per vos retenta faciemus vos et fratres predictos Milicie predicte facere semper tenere et habere, cum omnibus suis pertinenciis in pace et sine aliqua contradiccione et impedimento nostro et alterius cuiuslibet persone, vobis tamen et fratribus dicte Milicie paratis existentibus ${ }^{i}$ facere in posse nostri iudicis inde querelantibus iusticie complementum.

Quod est actum Dertuse, $\mathrm{XI}^{\circ}$ kalendas octobris, anno Domini $\mathrm{M}^{\circ} \mathrm{CC}^{\circ}$ $\mathrm{XC}^{\circ}$ quarto.

Signum Iacobi, Dei gracia regis Aragonum, Sicilie, Maioricarum et Valencie ac comitis Barchinone.

(1a. columna) Testes huius rei sunt Bernardus de Sarriano, miles, Raimundus Savina; (2a. columna) Raimundus de Minorisa, Artaldus Dezlor, Petrus Luppeti, scriptor domini regis; (3a. columna) Petrus de Libiano, Arnaldus de Bastida; (4a. columna) Guillelmus Galvayn, legum doctor, Guillelmi Calbeti, iurisperitus.

Sig(signe)num Guillelmi de Solanis, auxtoritate regia notarii publici per totam terram et dominacionem domini regis, qui hec scribi fecit et clausit loco, die et anno prefixis.

a. segueix ratllat de. - $b$. censum interlineat, damunt de tempus ratllat. - c. segueix ratllat site. - $d$. segueix ratllat et domibus. - $e$. segueix ratllat et aliis suis pertinenciis universis. Item, quendam locum vocatum Quintu, cum honoribus et possessionibus, terris, pratis et terminis ac suis pertinenciis universis. Item, quoddam pratum vocatum Aguilen, ubi olim consuevit esse 
mansus. - $f$. certum al manuscrit. - $g$. Ali interlineat, damunt de alii ratllat. - $h$. segueix ratllat que. - i. segueix ratllat paratis existentibus ius.

\section{RÉSUMÉ}

L'ordre militaire du Temple a déployé sur les terres de l'Èbre l'un des domaines territoriaux et juridictionnels les plus importants de la Couronne. Dans le présent article, la fin de ce seigneuriage est analysée, après la permutation réalisée avec Jacques II, en 1294, des territoires du royaume de Valence, dans le contexte de la politique royale de récupération de patrimoine et de rentes de la monarchie. L'auteur explique les causes directes de cette cession, comme la perte progressive de juridiction sur la ville, le propre déclin interne de l'ordre ou l'intérêt du roi pour la région de l'Èbre; ou encore l'étendue de l'échange et finalement les importsantes rétentions que les templiers y feront.

\section{SUMMARY}

The Military Order of the Knights of the Temple controlled in the region of the Ebro one of the most important territorial and jurisdictional domains of the Crown. This article analyses the end of this dominance, a result of the exchange made with Jaume II in 1294 for some lands in the kingdom of Valencia, in the context of the royal policy of recovering the patrimony and income of the monarchy. The author explains the direct causes of this cession such as the progressive loss of jurisdiction over the city, the internal decline of the Order itself and the king's interest in the Ebro region; also the extent of the exchange and, finally, the important holdings which the Templars retained there. 